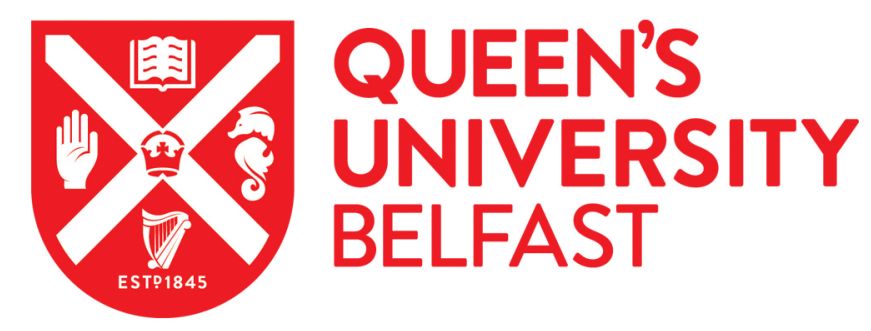

\title{
Exploring the impact of mindfulness on mental wellbeing, stress and resilience of undergraduate social work students
}

Roulston, A., Montgomery, L., Campbell, A., \& Davidson, G. (2017). Exploring the impact of mindfulness on mental wellbeing, stress and resilience of undergraduate social work students. Social Work Education, 37(2), 157-172. https://doi.org/10.1080/02615479.2017.1388776

Published in:

Social Work Education

Document Version:

Peer reviewed version

Queen's University Belfast - Research Portal:

Link to publication record in Queen's University Belfast Research Portal

Publisher rights

Copyright 2017 Taylor and Francis. This work is made available online in accordance with the publisher's policies. Please refer to any applicable terms of use of the publisher.

\section{General rights}

Copyright for the publications made accessible via the Queen's University Belfast Research Portal is retained by the author(s) and / or other copyright owners and it is a condition of accessing these publications that users recognise and abide by the legal requirements associated with these rights.

Take down policy

The Research Portal is Queen's institutional repository that provides access to Queen's research output. Every effort has been made to ensure that content in the Research Portal does not infringe any person's rights, or applicable UK laws. If you discover content in the Research Portal that you believe breaches copyright or violates any law, please contact openaccess@qub.ac.uk. 


\title{
Authors
}

Dr Audrey Roulston, Lecturer in Social Work, School of Social Sciences, Education and Social Work, Queen's University Belfast, 6 College Park, Belfast, Northern Ireland. a.roulston@qub.ac.uk

Dr Lorna Montgomery, Lecturer in Social Work, School of Social Sciences, Education and Social Work, Queen's University Belfast, 6 College Park, Belfast, Northern Ireland. 1.montgomery@qub.ac.uk

Dr Anne Campbell, Lecturer in Social Work, School of Social Sciences, Education and Social Work, Queen's University Belfast, 6 College Park, Belfast, Northern Ireland. a.campbell@qub.ac.uk

Dr Gavin Davidson, Senior Lecturer in Social Work, School of Social Sciences, Education and Social Work, Queen's University Belfast, 6 College Park, Belfast, Northern Ireland. g.davidson@qub.ac.uk

\begin{abstract}
Mindfulness is becoming more popular as emerging research demonstrates its benefits for self-care, by cultivating calmness and decreasing stress or anxiety. This pilot study aimed to measure the impact of a six-week Mindfulness course, modelled on the manualised treatment program developed by Kabat-Zinn, on the mental well-being, stress and resilience of undergraduate social work students in Northern Ireland.

This was a mixed methods study involving two groups: (1) intervention group participants who attended a six week Mindfulness course (April - May 2016) and (2) control group participants. Basic socio-demographic data were collected from all participants and all were invited to complete the Warwick-Edinburgh Mental Well-being scale, the Perceived Stress Scale and the Resilience Scale during weeks 1 and 6. Statistical tests were used to compare mean scores from the scales, and qualitative data were manually analysed using thematic content analysis.
\end{abstract}


Findings indicated significant changes in the scores for well-being, stress and resilience for the intervention group, but not for the control group. Mindfulness may not appeal to all students so should not be a mandatory component of training, but may be offered as one of the wider approaches to self-care for undergraduate social work degree students.

\section{Key words:}

Students, education, research minded practice, research, stress, organisations 


\section{Background}

There is evidence that mental wellbeing is a good indicator of how people and populations are able to function and thrive (Keyes, 2007). Past mental health research has focused on mental health problems and on the prevention of developing a mental disorder, rather than on mental wellbeing. Mental health has been more positively defined by the World Health Organisation (2014, p.1) as "a state of well-being in which every individual realizes his or her own potential, can cope with the normal stresses of life, can work productively and fruitfully, and is able to make a contribution to her or his community." In social work, Grant and Kinman (2014) have highlighted the need for organisations, educators and individual professionals to develop more positive approaches to managing the high levels of stress involved in practice. Additionally, they have identified the central importance of enhancing the wellbeing of social work students to ensure they are sufficiently resilient to manage the challenges of practice as they will be at the frontline of society's efforts to cope with many community, family and personal problems (Grant and Kinman, 2014). In order to tackle complex social problems and deliver better quality public services, it is necessary that effective self-care methods are integrated into each student's personal toolkit as they understand how their well-being can be improved. According to Botta, Cadet and Maramaldi (2015) health and social care professionals are increasingly integrating Mindfulness into their practice as emerging research demonstrates that it is one possible tool for self-care.

Mindfulness was modelled after the well-established manualised treatment program developed by Kabat-Zinn and colleagues at the University of Massachusetts. It can be thought of as "the ability to actively pay attention to the present moment and acknowledge and accept feelings without judging them as 'good' or 'bad'” (Parkes and Kelly, 2014, p. 110). Mindfulness practices are designed to enhance participants' ongoing awareness of their 
sensory experiences, thoughts, feelings, somatic sensations, and behaviours. Some concerns have been raised about the impact of developing Mindfulness in a more secular way, separated from its Buddhist foundations, as it has become broad in its definition, scope and application (Dylan and Coates, 2016). Nonetheless, it is intended that bringing greater awareness to actual experience in the "here and now" encourages a disengagement from self related thoughts (i.e. rumination) and emotions (i.e. anxiety) that can have a detrimental effect on well-being (Leary, 2004).

Findings suggest that Mindfulness is effective in facilitating neuroplasticity, improving emotion regulation, self-awareness and the ability to experience compassion (Pidgeon, Ford and Klaassen, 2014), and in cultivating calmness by decreasing stress or anxiety and improving the immune system (Jacobs et al., 2016). Many of these benefits were echoed by Weare (2014) who reported that Mindfulness practice may:

- Increase physical and emotional wellbeing, confidence, resilience, focus, concentration and ability to stay in the present moment, ability to cultivate self-compassion and kindness, emotional intelligence, attention and awareness.

- Improve responses to stress, the ability to make effective and balanced decisions and the ability to problem solve.

- Improve creativity, interpersonal relationships and skillfulness in communication.

Trowbridge and Lawson's (2016) systematic review of Mindfulness based interventions for social workers reported that although these benefits have been found across health and education literature, there was limited evidence available specifically on the effectiveness of Mindfulness with social workers. They did report that two studies (Bonifas and Napoli, 2013; McGarrigle and Walsh, 2011), which used quasi-experimental designs, had found that the use 
of Mindfulness had improved the social work students' and practitioners' ability to cope with stressful situations. Other findings suggest that Mindfulness can help social work practitioners by developing their ability to concentrate, calm and stabilise their minds (Gockel and Deng, 2016) although the processes by which this happens may not yet be fully understood (Rajan-Rankin, 2014). Research supports the fact that positive changes can occur through experiential learning and through Mindfulness practice (Hyland, Lee and Mills, 2015; Manotas, Segura, Eraso, Oggins and McGovern, 2014). As with most therapeutic processes, the quality of the relationships involved, for example between Mindfulness trainer and student, may also be a factor (Niehuis et al., 2016).

The rationale for this pilot study of Mindfulness in social work education was therefore comprised of: the research evidence of the stress that social workers experience; the growing evidence base for the benefits of mindfulness; the general responsibility that Universities have for the wellbeing of their students; the need for social work education to prepare students as well as possible for practice; and the relative lack of specific research exploring how effective Mindfulness could be for social work students managing the demands of qualifying training.

\begin{abstract}
Aims
The aim of this pilot study was to measure the impact of a six-week Mindfulness course on the mental well-being, stress and resilience of undergraduate social work students in Northern Ireland.
\end{abstract}

\title{
Methods
}

Ethical Approval 
The study was reviewed and approved by the School Research Ethics Committee in the participating University.

\section{Design}

This was a mixed methods study involving two groups of social work undergraduate students: (1) intervention group participants who attended a six week Mindfulness course (April - May 2016) and (2) control group participants who were recruited from a reserve list of students interested in attending the Mindfulness course.

\section{Recruitment}

Given the aim of the study, only students registered on the Bachelor of Social Work (BSW) degree were eligible to volunteer to attend of the six week Mindfulness course. Based on the nature of the course, 15 students could register to attend, and those expressing an interest were placed on a reserve list. Registered attendees were subsequently informed of the research project and advised that participation in the intervention group was voluntary, and not a requirement for attendance. Students on the reserve list were informed of the opportunity to volunteer and participate in the control group. The Participant Information Sheet and the consent form were circulated by email prior to convening an initial meeting with students interested in participating in the research. They were provided with an explanation about the project, consent and confidentiality. Prior to providing a written consent form, all were informed that they could change their mind regarding participation and withdraw from the research at any point, without consequence.

\section{Participants}


Thirty participants were recruited for the study at pre and post intervention junctures. Fifteen students completed baseline measurement for both the intervention and control groups. Thirteen intervention group participants and 12 control group participants completed questionnaires at the post intervention junctures. As outlined in Table 1 the mean age of the group was 29.0 (SD 9.70) with 25 females and 5 male social work students. The intervention group comprised 14 females and 1 male, whilst the control group had 11 females and 4 males. The intervention group consisted of four first year students who had completed two semesters of academic teaching in preparation for their first practice placement; ten second year students who had completed their first practice placement and one final year student who was completing the final practice placement. The control group consisted of eight first year students, six second year who were completing first placement and one final year student who was completing final placement.

Table 1. Details of Participants

\begin{tabular}{|l|l|l|}
\hline & Intervention group & Control group \\
\hline Gender & 1 & \\
Female & 14 & 4 \\
\hline Age (mean) & 29 & 11 \\
\hline Year of training & & 29 \\
First year & 4 & \\
Second year & 10 & 8 \\
Final year & 1 & 6 \\
\hline
\end{tabular}

\section{Intervention}

The Mindfulness intervention involved weekly two hour sessions which were modelled on the manualised treatment program developed by Kabat-Zinn (1982). Sessions included both 
didactic and experiential elements that focused on the training of five Mindfulness-based meditative practices. These practices involved learning how to pay attention on purpose through a series of techniques used to focus the mind and senses so that practitioners learn to slow down the competing thoughts and habitual or automatic reactions, in order to experience the present moment as it really is. A number of these techniques were taught during the workshops and integrated into a homework plan. These included: mindfully eating a raisin, mindfully brushing your hair, mindfully brushing your teeth and mindfully inserting a key into a lock. In addition, the body scan was utilsied. The body scan alternates focus of attention between specific aspects of one's body like a toe, to the entire body. Here the aim is to be aware of the different parts of the body, and allow oneself to experience how each part feels. The body scan helps to train one's mind to be able to move from detailed attention to a wider awareness from one moment to the next.

A new meditative practice was introduced each week to cultivate a receptive attention to all stimuli that enter the field of awareness on a moment-by-moment basis. Course participants were encouraged to practice them daily and retain a reflective diary to aid discussion with the trainer during group sessions.

The Mindfulness course was delivered by an experienced trainer, who has been accredited to use both Mindfulness Based Stress Reduction and Mindfulness Based Relapse Prevention. He has over 25 years' experience of teaching Mindfulness, and has taught experiential and practice based Mindfulness Programmes to organisations within the Health and Social Care, Education, Private and Public sectors throughout Northern Ireland.

\section{Data collection}


Basic socio-demographic data were collected from participants in the control group and the intervention group (age, gender, year on BSW degree). Intervention group participants were also asked to complete a questionnaire containing open-ended questions to outline their motivation for attending the course, their expectations surrounding the course, how they think attendance would benefit mental well-being, stress and resilience and how they anticipate the course helping them as a student social worker. Control group participants were also asked to indicate if they had any issues regarding mental well-being, stress and resilience. Quantitative data were collected from both groups to provide mental well-being, stress and resilience scores using the following three validated measurement scales at baseline (one hour prior to the course commencing) and weeks 6 (within one hour of the Mindfulness course concluding).

The Warwick-Edinburgh Mental Well-being scale (WEMWBS): originally conceived to assist in the monitoring of mental wellbeing in the general population. It has been validated for the measurement of mental well-being among people aged 13 to 74 in the UK (Tennant et al., 2009; Clark et al, 2001; Stewart-Brown, 2013). There are 14 items which are all worded positively and cover both feeling and functioning aspects of mental wellbeing (Tennant et al 2007). For example 'I've been feeling optimistic about the future'; 'I've been feeling useful'; 'I've been feeling relaxed'; and 'I've been feeling interested in new things'. It offers five response categories: 'none of the time', 'rarely', 'some of the time', 'often' and 'all of the time' meaning the respondent's score may range from 14-70. The authors do not specify a clinical cut off point score but the NHS Choice (2011) has indicated that 41 and 59 is an average score for mental well-being; 32-40 is below average and denotes some issues in relation to mental well-being for general populations; whilst 59-70 is perceived as above average for the general population. 
The Perceived Stress Scale (PSS) (Cohen 1983) is the most widely used psychological instrument for measuring the perception of stress. It is a 10-item measure of the degree to which situations in an individual's life are appraised as stressful. The items in the PSS are of a general nature and relatively free of content specific to any subpopulation group. They ask about respondents' feelings and thoughts during the last month, which are designed to gauge how unpredictable, uncontrollable and overloaded respondents find their lives. For example, 'In the last month, how often have you been upset because of something that happened unexpectedly?' and 'In the last month, how often have you felt that things were going your way?' Response options include $0=$ never, $1=$ almost never, $2=$ sometimes, $3=$ fairly often and $4=$ very often.

The Resilience Scale-14 (RS-14) was used to measure the degree of individual resilience. It is a shorter version of the original 25-item Resilience Scale (Wagnild, 1993). Statements include the following: 'I usually manage one way or another'; 'I usually take things in my stride' and 'I have self-discipline'. The degree of resilience perceived for each statement is rated on 7-point Likert scales ranging from 'strongly disagree' to 'strongly agree' (Losoi et al, 2013).

After the Mindfulness course ended in week 6, intervention group participants were invited to attend a focus group meeting to reflect on their experience of attending the course; how it helped them regarding mental well-being, stress and resilience; how they felt the course helped them personally or professionally; any advantages or disadvantages of attending the course; and if they would recommend Mindfulness to other students undertaking their social 
work training. With consent, the focus group meeting was audio recorded and professionally transcribed verbatim for analysis.

At week 12, participants were asked to complete open-ended questions to capture: the perceived advantages to attending the Mindfulness course; what elements of Mindfulness they were still practising; how they felt the course had helped with mental well-being, stress and resilience; what aspects of the course had helped personally and professionally; and if they would recommend the course to other social work students. Attempts were made to capture quantitative data from all participants at week 12 using the validated questionnaires, but insufficient returns resulted in this data being excluded from the final analysis.

\section{Data analysis}

\section{Statistical Tests}

A paired samples $t$ test was used to test the difference in means scores of the control and intervention groups for the WEMWBS, PSS and RS-14 psychometric tools. Differences between groups at baseline were assessed using independent t-tests, for the WEMWBS, PSS and RS-14 psychometric tools. Differences within groups before and after the intervention period were assessed using paired t-tests. Changes between groups before and after the intervention were compared using independent t-tests. Cohen's $d$ and the effect size correlation were determined for each psychometric test using the mean and standard deviation of the change.

\section{Qualitative analysis}

Data from the focus group interviews were analysed manually using the principles of thematic content analysis (Braun and Clarke, 2006). Fleming (2001) suggests four ways to improve credibility of qualitative research: reflexive analysis; participant checking 
data/report for accuracy; data saturation and inter-rater/peer checks. Inter-rater checks on the semi-structured interview data and transcript were carried out by two members of the research team. Qualitative comments captured in the focus group and individual comments captured through open-ended questions on the pre- and post-intervention questionnaires were manually analysed regarding well-being, stress and resilience.

\section{Ethical issues}

Mindfulness practice requires participants to embrace uncomfortable psychological phenomena and perceived imperfections (Kabat Zinn, 2003) and to manage the paradox of striving versus non-striving and sharing human vulnerabilities which may be challenging within the university peer group context (Solhaug et al, 2016). It was recognised that completing questionnaires or participating in focus group meetings about mental well-being, stress or resilience could be distressing for some participants. It was agreed that if a participant became distressed, data collection would be stopped and student counselling or support services would be recommended, if appropriate. It was agreed that if concerns were raised about scores or mental health, participants would be advised to seek support from their GP. At baseline two participants indicated that they had a history of depression and anxiety. When this was followed up both individuals indicated that they wished to continue to participate as they were already in receipt of support from their GP based on historical issues. Upon return of a completed consent form, participants were allocated a unique ID code.

Consent forms and completed questionnaires were securely stored in University premises. Audio recordings and transcriptions were stored securely on a password protected computer. All identifying details of participants were removed in the writing up of the research.

\section{Findings}




\section{Mental Well-being}

An examination of the WEMWBS scores between study and control groups at baseline showed a significant difference between groups $\mathrm{t}(28)=2.40, \mathrm{p}=0.02$, with a lower mean value in the intervention group (M 46.0 / SD 8.3 vs M 53.7 /SD 9.2). In general, the groups were reasonably comparable at the baseline although there was a difference in the WEMWBS score.

The WEMWBS was used to measure any change in well-being between the pre and post intervention phases. A paired samples $t$ test considered the possible difference in mean scores between the two groups in relation to their WEMWBS scores between times one and two. There was a significant increase in the WEMWBS score in the intervention group (46 (SD 8.3) pre-test vs $56.9(S D$ 6.7) post-test; $\mathrm{p}=0.00)$. There was a non significant decrease in the control group (53.7 (SD 9.2) pre-test vs. 46.9 (SD 8.5) post-test; $\mathrm{p}=0.06)$ (see Table 2).

Table 2. Pre /- Post-test Group Mean scores for Study and Control Group

\begin{tabular}{|l|l|l|l|l|}
\hline & & $\begin{array}{l}\text { M (SD) } \\
\text { Pre }\end{array}$ & $\begin{array}{l}\text { M (SD) } \\
\text { Post }\end{array}$ & p values \\
\hline WEMWBS & Study & $46(8.3)$ & $56.9(6.7)$ & $\mathrm{p}=0.00 * *$ \\
\hline PSS & Control & $53.7(9.2)$ & $46.9(8.5)$ & $\mathrm{p}=0.06$ \\
\hline & Study & $18.9(6.1)$ & $10.9(4.3)$ & $\mathrm{p}=0.01^{* *}$ \\
\hline RS-14 & Control & $15.0(6.4)$ & $13.3(5.9$ & $\mathrm{p}=0.10$ \\
\hline & Study & $76.0(12.6)$ & $83.5(8.9)$ & $\mathrm{p}=0.01 * *$ \\
\hline
\end{tabular}

M: Mean score SD: standard deviation. *Significant at $0.05 * *$ Significant at 0.01 .

An independent samples $t$ test indicated that the change in the intervention group score was significantly greater than that recorded for the control group (10.8 (SD 10.5) vs -4.0 (SD 7.3); $\mathrm{p}=0.00)$. The effect size for this analysis $(d=1.63)$ was found to exceed Cohen's $(1988)$ convention for a large effect $(d=.80)$ (see Table 3$)$. 
Table 3. Pre /- Post-Test Independent t tests Scores between Study and Control Groups

\begin{tabular}{|l|l|l|l|l|l|}
\hline & $M_{1}$ & $M_{2}$ & $p$ value & Cohen $d$ & Effect size $r$ \\
\hline WEBBS & $10.8(10.5)$ & $-4(7.3)$ & $p=0.00 * *$ & 1.63 & 0.63 \\
\hline PSS & $-7.9(-6.2)$ & $-1.7(3.6)$ & $p=0.00 * *$ & -1.22 & -0.52 \\
\hline RS-14 & $7.4(8.3)$ & $-4.0(8.4)$ & $p=0.02 *$ & 1.36 & 0.56 \\
\hline
\end{tabular}

*Significant at $0.05 * *$ Significant at 0.01 .

\section{Stress}

At baseline, perceived stress was identified by ten of the intervention group participants and nine of the control group participants which was generally attributed to academic assignments or exams with one reporting the cause as personal relationships/parental responsibilities. As described above, the PSS was used to measure students' perceptions of stress levels. An examination of the PSS scores between study and control groups at baseline showed a non-significant difference between groups $\mathrm{t}(28)=1.70, \mathrm{p}=0.09$. with a slightly higher mean value in the intervention group (M 18.9 / SD 6.1 vs M 15.0 /SD 6.4). Therefore the groups were comparable at the baseline although there was a difference in the PSS score.

A paired samples t test was also performed to measure any change in mean group score between the intervention and control groups between times one and two. There was a significant decrease in the PSS score in the intervention group (18.9 (SD 6.1) pre-test vs 10.9 (SD 4.3) post-test; $\mathrm{p}=0.01)$ and no significant decrease in the control group score (15.0 (SD 6.4) pre-test vs.13.3 (SD 5.9) post-test; $\mathrm{p}=0.10$ ) (see Table 2). An independent samples t test indicated that the change in the intervention group score was significantly greater than that in the control group (-7.9 (SD 6.2) vs $-1.7(S D$ 3.6); $\mathrm{p}=0.00)$. The effect size for this analysis $(d$ 
$=-1.26)$ was found to exceed Cohen's (1988) convention for a large effect $(d=.80)$ (see Table 3).

\section{Resilience}

The RS-14 was used to measure resilience in the intervention and control group participants. An examination of the RS-14 scores at baseline showed a non-significant difference between groups $t(28)=1.52, p=0.13$. with a slightly lower mean value in the intervention group $(\mathrm{M}$ 70.0 / SD 12.6 vs M 82.0 /SD 8.5). There was a significant increase in the RS-14 score in the intervention group (76.0 (SD 12.6) pre-test vs. 83.5 (SD 8.9) post-test; $\mathrm{p}=0.01)$ and a nonsignificant decrease in the mean score in the control group (82.0 (SD 8.5) pre-test vs. 77 (SD 15.1) post-test; $\mathrm{p}=0.10$ ) (see Table 2 ). An independent $\mathrm{t}$ test indicated that the change score in the intervention group was significantly greater than that in the control group (7.4 (SD 8.3) vs $-4.0(S D$ 8.4); $\mathrm{p}=0.02)$. The effect size $(\mathrm{d}=1.36)$ was greater than Cohen's $(1988)$ indicator for a large effect $(\mathrm{d}=.80)($ see Table 3$)$. The results showed that the programme had a significant positive effect on the resilience of programme participants.

\section{Well-being qualitative findings}

Qualitative data were obtained from intervention group participants through open-ended questions in questionnaires circulated at baseline (start of week 1) and follow-up (end of week 12) and through the focus group discussion (end of week 6). At baseline, participants had hoped the Mindfulness course would help improve their: well-being $(n=3)$; self-care $(n=3)$; understanding of well-being $(n=2)$; or anxiety management $(n=2)$. The remainder were unsure $(n=5)$. At week 12, participants indicated that the course improved insight and awareness. One indicated that since attending the course 'mental well-being has improved as I have noticed that I am more focused when performing tasks.' This student went on to 
indicate that the course had helped her 'personally to recognise my emotions and deal with them appropriately. I also feel more determined and focused than before I started this course. I am also more accepting of myself as a person.'

Another student indicated that the course had 'had a positive influence on [well-being] as it allowed me to become more aware of my feelings.' Another indicated they felt 'happier...more comfortable in my skin' or 'more positive and able to enjoy life more...taking time for myself...overall a more positive person.' She indicated the course had 'encouraged a dramatic positive mind shift and caused me to prioritise life priorities and gave me confidence to be my authentic self with happier life outcomes.'

This was reiterated in the focus group when one participant indicated the following:

'I feel a lot more like appreciative of the moment where before this course you were sort of thinking about...worrying about the future and the past. But I think it has changed me in a sense...even just sitting in the car or going out for a walk you feel happier. I don't know it sounds very simple when you put it that way. I feel more content with my life at the moment rather than worrying about the future.'

Some focus group participants felt that attending the course had given them permission to self-care. One cited the flying safety announcement of "putting the oxygen mask on yourself first, so it's about taking care of yourself before you can take care of others.' Another indicated that she had been 'living like a prisoner' and referred to 'that voice in my head telling me what to do all the time, and now I am living for me and telling it where to go.' She concluded that if she had not attended the Mindfulness course she "would still be listening to that voice and wouldn't have a life.' 
Overall, qualitative findings indicated that attending the course had increased self-awareness and insight into the students' emotions. Mindfulness had provided permission for students to prioritise themselves, to self-care, to feel content with their lives and more appreciative of the moment.

\section{Stress qualitative findings}

At baseline the intervention group participants indicated that they hoped the course would help them to recognise or manage stressors more effectively $(n=9)$ and cope with exam related stressors $(n=1)$. The remainder were unsure $(n=5)$. At week 12 some students indicated that they had felt less stressed during exams or assignment preparation, they felt better equipped to self-care and enjoy 'time out' and one shared their ability to 'use breathing exercises from the body scan to manage stress better.'

One student who had felt overwhelmed during placement last semester indicated that the Mindfulness course had helped develop confidence about how to manage stress in the future. Another indicated that the Mindfulness course had helped them to develop strategies to 'break negative cycles' of thinking and others hoped that practising breathing techniques would enable them to cope better with stress during assignments or placement next year. During the focus group at week 6 one student acknowledged how her attitude towards stressful situations such as 'being late' had changed and she can now enjoy life in the present. Another relayed how Mindfulness training had helped to manage stress regarding assignment submission:

'I know one of the things that he [trainer] said was when you are stressed you nearly feel more stress...your body craves more stress, and I was aware of that this week obviously because we have deadline and an assignment coming in and stuff and I was getting you know, I was thinking I need to do an assignment and I was then aware 
that's stress feeding stress and actually I'm not going to buy into that lets just deal with now. So it allowed me to deal with things with a clear head.'

Managing stress by regaining control was echoed by two other students. One found that 'focusing on my breathing and becoming aware of the present through sensory activity has helped to increase focus and concentrating which is most evident when studying or writing assignments, therefore reducing stress.' The other indicated that becoming more aware of the negative voice enabled them to consciously replace it with a positive mindset which they 'probably wouldn't have had that mind-set beforehand.' For others, the Mindfulness course helped to raise awareness of stressors, which included the multiplying of thoughts in your mind, stressing about something that might never happen or making up worst possible scenario stories in your head.

\section{Resilience qualitative findings}

Individual statements captured through the open ended questions in baseline questionnaires from the intervention group indicated that the majority of participants $(n=12)$ hoped that the Mindfulness course would help them to build/improve coping strategies and resilience, particularly when faced with challenging situations. The remainder were unsure how the course would benefit their resilience. Participants who returned questionnaires in week 12 indicated a continued use of the Mindfulness techniques and their perception that doing so had reduced stress and promoted resilience, particularly during the assessment period.

During the post-intervention focus group (week 6) three students believed that through attending the Mindfulness course they had developed resilience which would assist during future social work practice placements. This included believing the course 'has helped me to 
become better-rounded and more resilient, a quality essential after struggling on placement the year previously.' Another felt they had developed 'coping strategies for clearer professional decision-making when under pressure from the workload.' Another hoped they had built 'resilience as the next placement may include dealing with service users who are resistant to contact with social workers.' Some only engaged with exercises more fully after the course, which coincided with being off for the summer holidays.

\section{Recommending Mindfulness to other social work students}

Focus group participants shared their initial scepticism of Mindfulness and described it as a 'mystical' or 'alien concept'. Some initially felt unclear about the metaphors or analogies being used to explain Mindfulness, or felt uncomfortable with the body scan or undervalued the importance of self-care. Some described 'the body scan' used for guided meditation as 'weird' or 'bizarre.' Some participants revealed they initially felt 'terrified' of being hypnotised by the trainer due to the soothing rhythm of his voice: 'Just listening to his voice and the rhythm of it and the calm of it and I was just dropping and dropping and I think that's what frightened you, I think.' However, as the weeks passed, participants seemed to build a relationship of trust and Mindfulness made more sense meaning they felt more comfortable engaging in the exercises. However, those who remained sceptical confessed that they had been less committed to the homework tasks.

When asked if they would recommend the Mindfulness course to other BSW Degree students, there was a mixed response from the focus group participants. Whilst some participants were extremely positive about the course and the impact of Mindfulness on them

personally and professionally, one student recognised that 'it is not for everyone but I feel it is important to introduce it to SW students' and another suggested that 'it is vital to social 
work.' Individual qualitative statements returned by eight participants in week 12 questionnaires indicated that they found the Mindfulness course beneficial and had continued to practice Mindfulness. Others were less enthusiastic, particularly if the course needed private funding or if delivered in its current format. Most participants indicated that the course was too long, very time consuming and a few suggested that the information could have been condensed into an abbreviated course.

\section{Limitations}

This was a pilot study, which offered valuable insights into the benefits of the Mindfulness programme and the methodology used. There are a number of limitations to this study involving the sample size, convenience sampling and low returns at week 12 . The sample size was limited to a small number of course participants, based on the nature of the intervention. However, numbers recruited were matched with the control group. Convenience sampling was used to recruit self-selecting male and female students from the registration and reserve lists, which would not be representative of the student social work population. There are differences in the year of study across the sample, as some were further into their BSW Degree training than others. However, most had been exposed to direct social work practice through a practice placement or had undergone at least one academic year of BSW degree teaching. Attempts were made to collect data at three time points to capture baseline and follow-up at the end of the six week programme and at 12 weeks. Insufficient returns at week 12 resulted in quantitative data from week 12 being excluded from the analysis. However, comments captured at each point have been included. Unfortunately, not all participants from the intervention group attended the focus group meeting. The timing of the focus group and follow-up questionnaires was within one hour of the course completing. It could be suggested that participants were still in a Mindful state and the findings could be biased. However, the 
focus group data indicates that participants were able to objectively reflect on the course content, delivery and impact. Although there was evidence of sample attrition at follow-up, the response rate remained at $80 \%$. Given the rising popularity of Mindfulness and the focus on supporting individuals with uncomfortable psychological phenomena it is important that Mindfulness trainers are experienced in Mindfulness and understand anxiety and depression (Solhaug et al, 2016). Our trainer was a very experienced practitioner and teacher who adopts a consistent approach when teaching this course but there was no way for controlling how his approach or personality may have influenced student perceptions towards the Mindfulness programme or its impact on the group dynamics when engaging in the five Mindfulness practices. Although the results indicate significant improvements in the mental well-being, stress and resilience of the intervention group, there is no way of knowing if these were attributed to the Mindfulness course, the effects of other support systems external to the University or social support generated over the six week programme.

\section{Discussion}

The aim of this pilot study was to measure the impact of a six-week Mindfulness course on mental well-being, stress and resilience of undergraduate social work students. Findings indicated that there were significant changes in the scores for well-being, stress and resilience for the intervention group, but not for the control group. Although not significant, there seems to be evidence that wellbeing worsened over time for control group participants. Given the stressful nature of social work as a profession, this highlights the importance of protecting wellbeing in undergraduate students as they use Mindfulness as one avenue for listening to their inner worlds of bodily sensations, needs and stressors (Solhaug et al, 2016). The significant increase in the well-being scores for the intervention group was supported by qualitative comments confirming newfound self-awareness, positivity and self-care, as well 
as freedom to 'live in the moment'. Other studies have reported that Mindfulness is a tool for self-care (Botta et al, 2015); can increase self-awareness by promoting the ability to stay in the moment (Birnbaum, 2008; Pidgeon et al, 2014); can transform individuals (Lynn, 2010) and legitimise self-care and self compassion (Smeets et al, 2014).

Similarly, findings indicated that there was a significant decrease in perceived stress scores in the intervention group, whereas there was no significant decrease in the control group. Qualitative comments supported this and indicated that the Mindfulness programme had enabled students to manage stress surrounding exams or assignments with specific techniques and had heightened awareness of potential stressors. Similar findings were also reported by Jacobs et al (2016) who suggested that Mindfulness was effective in cultivating calmness by decreasing stress and anxiety. Birnbaum (2008) used Mindfulness meditation to enhance self awareness and increase the students' ability to handle practice fieldwork and academic stressors, which mirrored techniques used in our Mindfulness programme and the outcomes identified by participants.

The results showed that the Mindfulness programme had a significant positive effect on the resilience scores for programme participants. Although some of the participants remained sceptical about or felt uncomfortable with aspects of the course, focus group participants who had embraced the course content and homework exercises reported positive benefits and felt more able to manage exam related stress or anticipated using these exercises during future practice placements or stressful life events. Wong (2004) reported that the moment of discomfort was significant in terms of becoming more conscious of habitual labelling or judging of themselves or others, which supports the transition some participants made from feeling bewildered of confused to embracing Mindfulness and reporting life-changing 
benefits. Although it has been suggested that more research is required regarding the benefits of Mindfulness for developing resilience (Lynn, 2010), our research findings indicate there were very clear benefits for all course participants.

Although some students found the introduction to Mindfulness 'mystical' or initially feared the 'hypnotic' potential of the trainer's voice, this altered as trust in the therapeutic relationship developed over time. As indicated in the literature, the quality of relationship between therapist and student may be a factor in promoting well-being (Niehuis et al., 2016). Likewise, although some were critical about the timing or duration of the sessions, there was a general sense of commitment to attending the sessions. When exploring the perceived usefulness of the Mindfulness training for social work students, participants indicated that they could see benefits, particularly in relation to developing coping strategies for stressful events such as exams, assignments or practice placements. This is similar to findings from Birnbaum (2007), who indicated that students developed better concentration and focus through Mindfulness meditation, which helped them to write academic assignments. In addition, emerging literature appears to suggest that Mindfulness may improve empathy, compassion and listening, which are all essential for the social work professional (Lynn, 2010) and may enable students to develop containing and self-regulating emotions (Birnbaum, 2007). Trowbridge and Mische Lawson (2016), in their systematic review of literature pertaining to Mindfulness-based interventions with social workers, identified Mindfulness as a potential protective factor for SW students entering the workplace.

The present small scale study has been useful in informing decisions about the integration of Mindfulness training into the curriculum for social work education in one university, highlighting issues around the structure, format and timing or the Mindfulness course. Key 
issues for consideration emerging from this study were similar to those identified by Gockel and Deng (2016), who facilitated and evaluated a similar Mindfulness programme for Masters in Social Work students in North America. In developing Mindfulness training as part of the curriculum for social work education, decisions around the voluntary or required nature of Mindfulness training, its integration into core academic modules such as social work theory or skills development, or alternatively, the promotion of distinct, stand alone, non-assessed Mindfulness workshops should be considered. Other key variables include the length, content and timing of the course; brief but regular sessions have been positively utilised (Raheim and Lu, 2014), as have the advantages of longer periods of Mindfulness practice (Gockel and Deng, 2016). The goals of the Mindfulness training were also considered. Whilst the focus of this evaluation was on specific factors associated with student functioning: well-being, stress and resilience, a wider application of Mindfulness has been noted in the literature. Benefits have been found in a number of areas, including: promoting increased empathy (Krasner et al, 2009); enabling social work students to integrate theory into practice; integrating Mindfulness into students professional and personal self (Lynn and Mensinga, 2016), engaging in critical reflection, and considering issues of class, power and oppression, (Gockel and Deng, 2016: Wong, 2013).

\section{Conclusion}

Findings indicated that the six-week Mindfulness course appeared to enhance well-being, improve stress and resilience scores, but it may not appeal to all students so should not be a mandatory component of training, but may be offered as one of the wider approaches to selfcare for undergraduate social work degree students. Grant et al. (2015) have argued for the development of an 'emotional curriculum' in social work education and Mindfulness has the potential to provide one of the many evidence based components needed. 



\section{References}

Abiola, T., \&Udofia, O. (2011). Psychometric assessment of the Wagnild and Young's resilience scale in Kano, Nigeria. BMC Research Notes, 4, 509. doi: 10.1186/1756-0500-4509.

Botta, A., Cadet, T., \& Maramaldi, P. (2015). Reflections on a Quantitative, Group-Based Mindfulness Study with Social Work Students. Social Work With Groups, 38(2), 93-105. doi: $10.1080 / 01609513.2014 .975885$.

Birnbaum, L. (2005). Connecting to inner guidance: Mindfulness meditation and transformation of professional self-concept in social work students. Critical Social Work, 6 (2) [online]. Available at: http://www.criticalsocialwork.com, accessed 19 September 2008. Birnbaum, L. (2008). The use of mindfulness training to create an "accompanying place" for social work students. Social Work Education The International Journal, 27(8), 837-852. [online]. doi: 10.1080/02615470701538330.

Bonifas, R. P., \& Napoli, M. (2014). Mindfully increasing quality of life: A promising curriculum for MSW students. Social Work Education, 33(4), 469-484.

Braun, V., \& Clarke, V. (2006). Using thematic analysis in psychology. Qualitative Research in Psychology, 3(2), 77-101. doi: 10/1191/1478088706qp063oa.

Clarke, A., Friede, T., Putz, R., Ashdown, J., Martin, S., Blake, A.,...Stewart-Brown, S. (2011). Warwick-Edinburgh Mental Well-being Scale (WEMWBS): Validated for teenage school students in England and Scotland. A mixed methods assessment. BMC Public Health, 11, 487-495. doi: 10.1186/1471-2458-11-487.

Cohen, S., Kamarck, T., \& Mermelstein, R. (1983). A global measure of perceived stress. Journal of Health and Social Behaviour, 24(4), 385-396. View in Pub Med: http://www.ncbi.nlm.nih.gov/pubmed/6668417 
Crawford, M.J., Robotham, D., Thana, L., Patterson, S., Weaver, T., Barber, R., Wykes, T., $\&$ Rose, D. (2011). Selecting outcome measures in mental health: the views of service users. Journal of Mental Health, 20, 336-346. doi: 10.3109/09638237.2011.577114.

Dylan, A., \& Coates, J. (2016). Introduction to Special Issue: Mindfulness and Social Work, Journal of Religion \& Spirituality in Social Work: Social Thought, 35, 1-6. doi:

$10.1080 / 15426432 / 2015.1080606$.

Gockel, A., \& Deng, X. (2016). Mindfulness training as social work pedagogy: Exploring benefits, challenges, and issues for consideration in integrating mindfulness into social work education, Journal of Religion \& Spirituality in Social Work: Social Thought, 35(3), 222-244. doi: 10.1080/15426432.2016.1187106.

Grant, L., \& Kinman, G. (2012). Enhancing wellbeing in social work students: Building resilience in the next generation. Social Work Education, 31(5), 605-621.Grant, L., \& Kinman, G. (Eds.). (2014). Developing resilience for social work practice. London: Palgrave Macmillan.

Grant, L., Kinman, G., \& Baker, S. (2015). Put on Your Own Oxygen Mask before Assisting Others': Social Work Educators' Perspectives on an 'Emotional Curriculum. British Journal of Social Work, 45(8), 2351-2367.

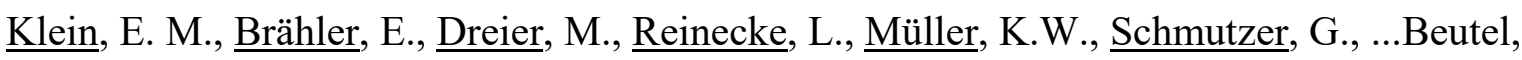
M. E. (2016). The German version of the Perceived Stress Scale - psychometric characteristics in a representative German community sample. BMC Psychiatry, 16, 159-169. doi: 10.1186/s12888-016-0875-9.

Krasner, M. S., Epstein, R. M., Beckman, H., Suchman, A. L., Chapman, B., Mooney, C. J., \& Quill, T. E. (2009). Association of an educational program in mindful communication with burnout, empathy, and attitudes among primary care physicians. Jama, 302(12), 1284-1293. 
Hyland, P., Lee, R., \& Mills, M. (2015). Mindfulness at Work: A New Approach to Improving Individual and Organizational Performance. Industrial \& Organizational Psychology, 8 (4), 576-602. doi: 10.1017/iop.2015.41.

Jacobs, T. L., Epel, E. S., Lin, J., Blackburn, E.H., Wolkowitz, O. H., Bridwell, D.A., ...Saron, C. D. (2011). Intensive meditation training, immune cell telomerase activity, and psychological mediators. Psychoneuroendocrinology, 36 (5), 664-681. doi: 10.1016.

Kabat-Zinn, J. (1982) An outpatient program in behavioral medicine for chronic pain patients based on the practice of mindfulness meditation: theoretical considerations and preliminary results. General Hospital of Psychiatry, 4(1), 33-47.

Kabat-Zinn, J. (2003). Mindfulness-based interventions in context: past, present, and future. Clinical Psychology: Science and Practice, 10(2), 144-156.

Keyes, C.L.M. (2007). Promoting and protecting mental health as flourishing: A complementary strategy for improving national mental health. American Psychologist, 62: 95.

Leary, M.R. (2004). The curse of mindfulness: self-awareness, egotism and the quality of human life. New York: Open University Press.

Manotas, M., Segura, C., Eraso, M., Oggins, J., \& McGovern, K. (2014). Association of brief mindfulness training with reductions in perceived stress and distress in Colombian health care professionals. International Journal of Stress Management, 21, 207-225. doi: 10.1037/a0035150.

Losoi, H., Turunen, S., Waljas, M., Helminen, M., Ohman, J., Julkunen, J., \& Rosti-Otajarvi, E. (2013). Psychometric properties of the Finnish Version of the Resilience Scale and its Short Version. Psychology, Community and Health, 2(1), 1-10. doi: 10.5964/pch.v2i1.40. Lynn, R. (2010). Mindfulness in Social Work Education. Social Work Education, 29(3), 289304. doi:10.1080/02615470902930351. 
McGarrigle, T., \& Walsh, C. A. (2011). Mindfulness, self-care, and wellness in social work: Effects of contemplative training. Journal of Religion \& Spirituality in Social Work: Social Thought, 30(3), 212-233.

Nienhuis, J.B., Owen, J., Valentine, J.C., Black, S. W., Halford, T.C., Parazak, S.E., Budge, S. \& Hilsenroth, M. (2016). Therapeutic alliance, empathy, and genuineness in individual adult psychotherapy: A meta-analytic review. Psychotherapy Research, published online 7 July 2016, 1-13. doi: 10.1080/10503307.2016.1204023.

Parkes, R. \& Kelly, S. (2014). Mindfulness for resilience in social work in Grant, L., \& Kinman, G. (Eds.). (2014). Developing resilience for social work practice (pp. 110-126). London: Palgrave Macmillan.

Pidgeon, A.M., Ford, L., \& Klaassen, F. (2014). Evaluating the effectiveness of enhancing resilience in human service professionals using a retreat-based mindfulness with Metta Training Program: A randomised control trial. Psychology, Health and Medicine, 19, 355-64. doi: $10.1080 / 13548806.2013 .806815$.

Raheim, S., \& Lu, J. J. (2014). Preparing msw students for integrative mind-body-spirit practice. Clinical Social Work Journal, 42(3), 288-301.

Rajan-Rankin, S. (2014). Self-identity, embodiment and the development of emotional resilience. British Journal of Social Work, 44 (8): 2426-2442.

Smeets, E., Neff, K., Alberts, H., \& Peters, M. (2014). Meeting suffering with kindness: effects of a brief self-compassion intervention for female college students. Journal of Clinical Psychology, 70(9), 794-807.

Solhaug, I., Eriksen, T. E., de Vibe, M., Havvind, H., Fribory, O., Sorlie, T. \& Rosenvinge, J. H. (2016). Medical and psychological students' experiences in learning mindfulness: Benefits, paradoxes and pitfalls. Mindfulness, 7(4), 838-850. doi: 10.1007/s12671-016-05210 
Stewart-Brown, S. (2013). The Warwick Edinburgh Mental Well-being Scale (WEMWBS): Performance in different cultural and geographical groups. In: C. L. M. Keyes (Ed.), Mental Well-Being: International contributions to the study of positive mental health (pp. 133-150). Atlanta: Springer.

Tennant, R., Hiller, L., Fishwick, R., Platt, S., Joseph, S., Weich, S., Parkinson, J., Secker, J. \& Stewart-Brown, S. (2007). The Warwick-Edinburgh Mental Well-being Scale (WEMWBS): development and UK validation. Health and Quality of Life Outcomes 5: 63. doi: $10.1186 / 1477-7525-5-63$.

Trowbridge, K., \& Lawson, L.M. (2016). Mindfulness-based interventions with social workers and the potential for enhanced patient-centered care: A systematic review of the literature, Social Work in Health Care, 55(2), 101-124. doi:

10.1080/00981389.2015.1094165.

Wagnild, G. M., \& Young, H. M. (1993). Development and psychometric evaluation of the resilience scale. Journal of Nursing Measurement, 1, 165-178.

Wagnild, G.M. (2009). The Resilience Scale user's guide for the US English version of the Resilience Scale and the 14-Item Resilience Scale (RS-14). Worden, MT: The Resilience Center.

Weare, K. (2014). Evidence for Mindfulness: Impacts on the Wellbeing and Performance of School Staff. Exeter: University of Exeter.

Wong, Y. (2004). Knowing through discomfort: A mindfulness-based critical social work pedagogy. Critical Social Work, 5(1) [online]. uwindsor.ca/criticalsocialwork/knowingthrough-discomfort-a-mindfulness-based-critical-social-work-pedagogy accessed 28 September 2016. 
World Health Organisation (2014) Mental health: a state of well-being. [Accessed online at http://www.who.int/features/factfiles/mental health/en/ on 12/02/17. Geneva: World Health Organisation. 